\title{
A TEACHING STRATEGY TO UNDERSTAND THE SOLID STATE CHEMISTRY FOR HIGH LEVEL EDUCATION STUDENTS: AN EXPERIENCE WITH A PHOSPHORESCENCE MATERIAL
}

\author{
Viktorija Stilbytė, Iván Peña-Huguet, Marta Pérez-Maseda, Andrés Mollar-Cuni, \\ María Gutiérrez-Blanco, Celia M. Rueda, Pablo Serna-Gallén, Maria Fortuño- \\ Morte, Héctor Beltrán-Mir, Eloísa Cordoncillo
}

Departament de Química Inorgànica i Orgànica. Universitat Jaume I (SPAIN)

\begin{abstract}
Solid state chemistry has attracted the attention of many fields due to its wealthy chemistry as well as the versatility of its applications. Among the wide fields in this area, the light interaction with a solid has been selected in this experience to understand the phosphorescence process in a material. This experience will allow students to understand an amazing phenomena which occurs in our quotidian life as the light emission of fireflies, stickers or fireworks. A teaching strategy has been proposed for undergraduate chemistry students, introducing them to the concepts of phosphorescence as well as different techniques of characterization through a simple laboratory session based in the synthesis of a phosphor material. Nowadays, it is a challenge to encourage students to properly understand chemistry and materials science due to the importance that represents in our society.

Luminescence is a spontaneous light emission coming from excited electronic states after the absorption of UV/visible light. These processes include triboluminescence, fluorescence, phosphorescence, chemiluminescence and bioluminescence. In particular, phosphorescence visible light on slow (minute to hour) time scales after the excitation source has been removed. Lanthanidedoped strontium aluminate $\left(\mathrm{Eu}: \mathrm{SrAl}_{2} \mathrm{O}_{4}\right)$ is one of the most widely used phosphor owing to its green environmental properties and their excellent features, like their long-lasting phosphorescence or their potential applications in optoelectronic devices.

The aim of this work is showing an example to understand this energetic concept from the preparation of a phosphorescent material based on the strontium aluminate structure. A new methodology of synthesis derived of the Pechini's method has been introduced to the students. The importance of lanthanides ions has also been highlighted. Two common characterization techniques in Solid State Chemistry are presented to the students: X-Ray Diffraction and Electron Microscopy. Finally, phosphorescence properties have been studied in order to bring them closer in the complete preparation of a material. It has allowed them to keep in contact during the whole experiment with the three main concepts of Materials Science: synthesis, structure and properties. This fact makes the work interesting not only from the point of view of students, also for teachers of inorganic chemistry and material science and undergraduate students owing to its pedagogical character employing a Problem Based Learning.
\end{abstract}

Keywords: Solid state, inorganic chemistry, phosphorescence, materials science.

\section{INTRODUCTION}

Stone, bronze and iron civilizations have been defined by Man's relationship with materials. The employment of materials for feeding, clothing, and protection not only distinguished human beings from other animal life but ensured the survival and ascendency of our species. Materials have now become so thoroughly ingrained into society that they are often overlooked or underappreciated. When we turn on a light switch, the fact that we are effectively employing hundreds of different materials is hardly apparent to the casual observer. From the glass, metals and polymers that make up the light bulb to the wires that connect it, via switches and meters, to the power plant that generates the electricity, we are intimately dependent on a wide range of materials which we ordinarily take for granted [1].

In the last few years, the development of chemistry has been focused on the search of advanced materials which possess improved features such as higher mechanical strength, better values of electrical conductivity, etc. Moreover, there is a huge interest in the preparation of materials with new and unique properties such as luminescence. Luminescence compounds have been found attractive 
due to their versatile applications in many fields, ranging from luminescent signals to cancer therapy. Nowadays, the functionality and success of many lighting and displays systems have inorganic luminescent materials as key components, which are included in many devices such as TV sets, monitors and medical scanners.

When an atom or molecule absorbs energy, it enters an unstable excited state. To return to its ground (or resting) state, it must find a way to divest itself of the excess energy. The nature of how the system gets excited, and what excited energy level the system is in, will determine whether the process of light emission is classified as incandescence or luminescence. Incandescent processes are always caused by heating a material until it glows, while the luminescence is produced when light is emitted without simultaneous change in temperature [2]. Luminescence emission occurs after an appropriate material has absorbed energy from a source such as visible, ultraviolet, X-ray radiation, electron beams, chemical reactions, and so on. Therefore, luminescence can occur as a result of many different kinds of excitation, which is reflected in expressions such as photo-, electro-, chemi-, thermo-, sono-, or triboluminescence [3-4]. These processes can be summarized in Fig. 1.

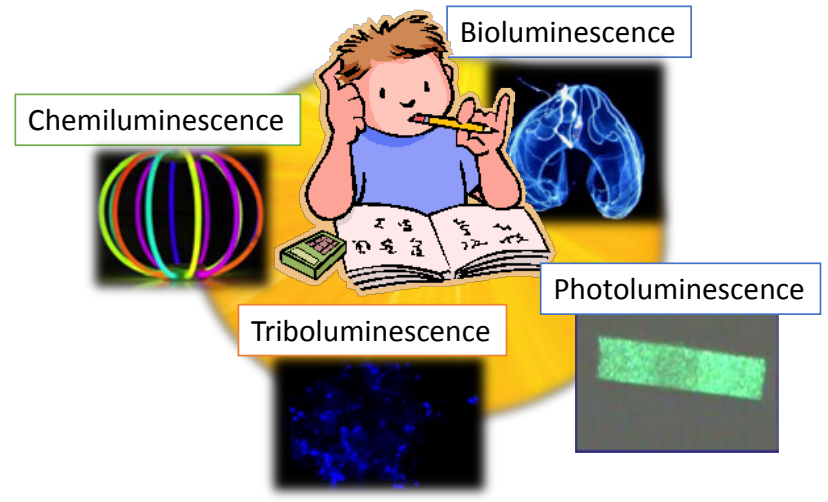

Figure 1. Possible luminescent fates for an atom or molecule after electronic excitation.

Excitation of a material by ultraviolet or visible light photons giving light emission is a phenomenon termed photoluminescence and is divided into two categories: fluorescence and phosphorescence, depending upon the electronic configuration of the excited state and the emission pathway.

Fluorescence is the property of some atoms and molecules to absorb light at a particular wavelength and reemit it almost immediately (within about $10^{-8}$ seconds) in longer wavelength. In this case, an electron is raised from a certain baseline energy known as the ground level to an excited level, and the transition of the electron back to the ground level is what generates spontaneous emission. Since remission occurs so quickly, the fluorescence ceases as soon as the exciting source is removed. The process of phosphorescence occurs in a manner similar to fluorescence, but light emission persist longer in time (usually seconds to hours) even the exciting source is no longer applied.

Educational methodologies are going to be used to study and understand these materials with phosphorescence properties. Problem-Based Learning (PBL) is a pedagogic tool employed as vehicle to promote student learning of concepts and principles. It is based on the idea that the student looks up the solution of a real problem. This methodology allows students to promote the development of critical thinking skills, problem-solving abilities, and communication skills by their own work. For this reason, PBL is a technique used by teachers and lecturers in their courses at many areas of study. This method could be used to get a better understanding of materials present in different objects of our quotidian life. To apply this tool, in this work we propose an example for understanding the luminescent character of a lanthanide-doped strontium aluminate, $\mathrm{Ln}: \mathrm{SrAl}_{2} \mathrm{O}_{4}$, in particular the phosphorescent features, including the synthesis and characterization of this material. This methodology make the work interesting not only from the point of view of students, also for teachers of inorganic chemistry and material science and undergraduate students owing to its pedagogical character employing a Problem Based Learning.

A phosphorescent material based on europium doped $\mathrm{SrAl}_{2} \mathrm{O}_{4}$ was synthesized and characterized by the students, and it was irradiated with different wavelengths in order to observe its response to the excitation. The students could observed the light emission of the material irradiated from emission spectra. The following steps were proposed to the students before the experimental parts to have a better understanding of the problem. 
+ First, students define the fluorescence and phosphorescence terms.

The phosphorescence, as listed, is a type of luminescence. The compound absorbs the light radiation going from the ground state to an excited state of energy with the same multiplicity, and the transition of the electron back to the ground level lead to fluorescence or phosphorescence phenomenon. When the ground state and the excited state have the same multiplicity, for example singlet, the fluorescence is produced. However, in determined materials could occur a crossing system ("intersystem crossing") from the singlet excited state to the triplet excited state (electrons are not paired) [4]. Although this process is forbidden by the spin rule, it takes place sometimes bringing on a radiative relaxation, which is named phosphorescence. A simplify scheme of this process is shown in Fig. 2.

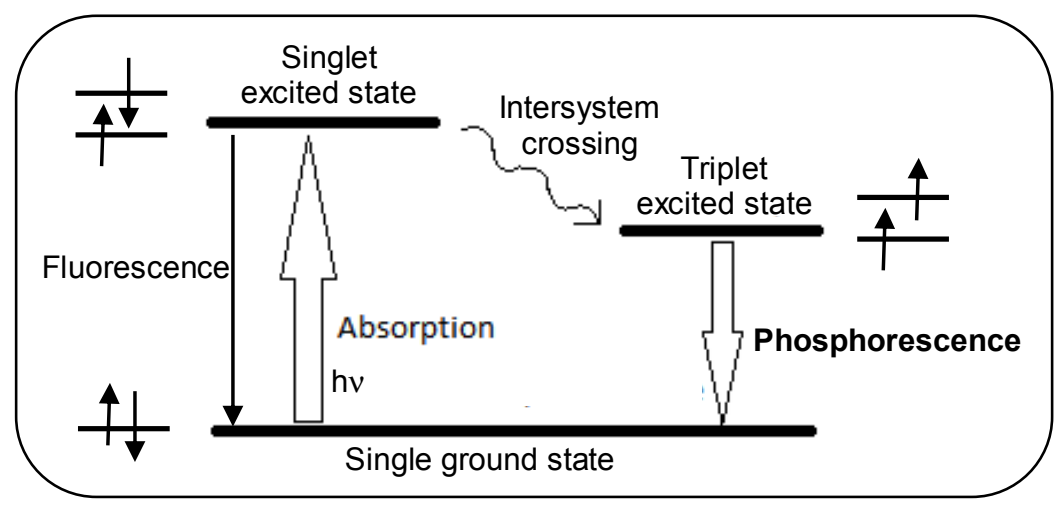

Figure 2. Photoluminescence processes showing absorption, intersystem crossing and emission.

+ Second, once the students know the luminescence process, they deep into the system which generates phosphorescence in this work.

Strontium aluminate $\left(\mathrm{SrAl}_{2} \mathrm{O}_{4}\right)$ is one of the most promising host materials for long afterglow luminescence [5]. $\mathrm{SrAl}_{2} \mathrm{O}_{4}$ has a stuffed tridymite-like structure built up of layers of $\left[\mathrm{AlO}_{4}\right]^{5-}$ tetrahedra sharing corners that give rise to six corner rings. $\mathrm{Sr}^{2+}$ ions are located in the cavities of the framework of $\left[\mathrm{AlO}_{4}\right]^{5-}$ tetrahedra, occupying two different sites with low symmetry and coordinated by nine oxygen atoms [6].

The aluminate $\mathrm{SrAl}_{2} \mathrm{O}_{4}$ exists in two crystallographic forms: monoclinic and hexagonal. The monoclinic phase (M) is stable at low temperature [7]. $\mathrm{SrAl}_{2} \mathrm{O}_{4}$ in its monoclinic phase structure is a well-known host for a high efficient phosphor material when doped with divalent europium $\left(\mathrm{Eu}^{2+}\right)$ as the activator. The preparation of $\mathrm{SrAl}_{2} \mathrm{O}_{4}$ as single phase by conventional methods requires temperatures above $1900^{\circ} \mathrm{C}$. It is therefore a technological issue to reduce this temperature with other synthesis methods, for example Pechini's method, or using mineralizers such as $\mathrm{B}_{2} \mathrm{O}_{3}$. This compound is a well-known glass former, which has a low melting point around $460^{\circ} \mathrm{C}$. It is regarded as an excellent flux to facilitate the material diffusion. Thus, $\mathrm{B}_{2} \mathrm{O}_{3}$ is usually added in the preparation of $\mathrm{SrAl}_{2} \mathrm{O}_{4}$ to reduce the synthesis temperature [8].

\section{+ Third, they study how this phenomenon is measured.}

The luminescence is measured by emission spectroscopy. In this type of spectroscopy, a photon of energy $h v$ strikes an atom or molecule and absorption may occur if the difference in energy, $\Delta E$, between the ground state and the excite state is equal to the photon's energy. After excitation, they will relax to lower energy levels and will emit radiation corresponding to the energy differences between the various energy levels of the quantum system. Thus, the emission lines have a characteristic "fingerprint" that can be associated with a unique atom, ion, or molecule. In this work, we studied the emission spectrum of europium using two excitation energies: 340 and 394 nanometres.

\section{+ Finally, at this point, students look for the wide variety of phosphorescent materials applications.}

Everybody know that this materials are present in quotidian objects in our life like glow-in-the-dark stickers, toys or clock dials. However, it are also present in many unknown and important applications. For example paints, phosphorescent pigments and emergency signals that can shine for many hours without source of energy [9-10]. 


\section{CHARACTERIZATION TECHNIQUES}

One of the aims of this work is to introduce students the two most common techniques used in Solid State Chemistry and show them the potential of these techniques to characterize solid materials. In order to characterize the crystalline structure of the host network, $\mathrm{SrAl}_{2} \mathrm{O}_{4}$, one of the most important techniques in Solid State Chemistry was used: X-Ray Diffraction (XRD). In addition, the luminescence response was studied through photoluminescence emission (PL). The main characteristics of these techniques are explained below.

\subsection{X-Ray diffraction (XRD)}

The X-Ray diffraction is the most frequently tool used for the study of crystalline solids and one of the most important techniques of the solid state. This technique has been used since the early XX century as a method of characterization, monitoring of reactions, phase transitions, thermal expansion, determination of unit cell parameters, etc. XRD is based on the diffraction phenomenon that occurs when a beam X-Ray impinges on a crystalline sample.

By analogy with the diffraction by an optical network (1-D), crystals with structures which are repeated regularly should diffract the radiation with a similar $\lambda$ to the interatomic separation $\sim 1 \AA$. The $\lambda$ of the $X-$ ray commonly used is the characteristic radiation $\mathrm{K}_{\alpha}$ emitted by the $\mathrm{Cu}, \lambda=1.5418 \AA$.

Bragg proposed a model in which the crystals are formed by planes, so each crystal acts as a semitransparent mirror. Some of the rays are reflected in the plane with the angle of reflection equal to the incidence angle, but the rest of the rays will be reflected by the following planes. These reflections are capable to combine constructively or destructively, depending on the interplanar distance $(d)$. The condition for constructive interference to occur is:

$$
2 d \operatorname{sen} \theta=\mathrm{n} \lambda
$$

This is known as Bragg's Law for X-Ray diffraction, where the path difference between two waves undergoing constructive interference is given by $2 d \sin \theta, \theta$ is the scattering angle (Bragg angle), $\mathrm{n}$ is reflexion order $(n=1,2,3 \ldots), \lambda$ is the wavelength of the incident radiation applied in the sample, and $d$ is the interplanar distance [10].

When Bragg's Law is satisfied, the reflected beams are in phase and interfere constructively. These interferences can be represented in a diffractogram, which is characteristic for each crystal and can be used to identify, principally, inorganic systems in Solid State Chemistry.

Today, the entire well known systems and the new developed compounds are identified by X-Ray diffraction and exists a data base called JCPDS-ICDD (Journal Committee Powder Diffraction Standard-International Centre for Diffraction Data) that contains their diffractograms. If a diffractogram of a new material is stored in this data base, its characterization can be done.

In this work, phase analysis was performed by X-Ray powder diffraction (XRD) with a Bruker AXS D4 Endeavor diffractometer with $\mathrm{CuK}_{\alpha}$ radiation. Data were collected by stepscanning over a $2 \theta$ range from $15^{\circ}$ to $70^{\circ}$ with a step size of $0.05^{\circ}$ and $5 \mathrm{~s}$ counting time at each step. The goniometer was controlled by the "DIFFRACT plus" software, which also determined diffraction peak positions and intensities. Instrument was calibrated using an external Si standard.

\subsection{Photoluminescence (PL) of Europium}

Lanthanide ions are special in photonics because of their unique photophysical properties. Namely high luminescence quantum yields may be obtained for essentially narrow bandwidth, long lived emission bands, lying from the UV to the NIR spectral regions, arising from $4 \mathrm{f}-4 \mathrm{f}$ parity and spin forbidden transitions. Among them, $\mathrm{Eu}(\mathrm{III})$ has a simple level structure which allows the absorption and emission spectroscopy in the visible range.

$\mathrm{Eu}(\mathrm{III})$ has a $[\mathrm{Xe}] 4 f^{6}$ electronic configuration. The $4 f$ electrons can be arranged in different ways (microstates) into the seven $4 f$ orbitals. These microstates are grouped into different terms of energy. These terms generated different transitions as can be observed in Fig 3. Therefore, Eu(III) compounds show an intense photoluminescence due to ${ }^{5} D_{0} \rightarrow{ }^{7} F_{j}$ transitions (where $j$ takes values $0-6$ ) from the excited state $\left({ }^{5} D_{0}\right)$ to the $j$ levels of the ground term ${ }^{7} \mathrm{~F}$. 


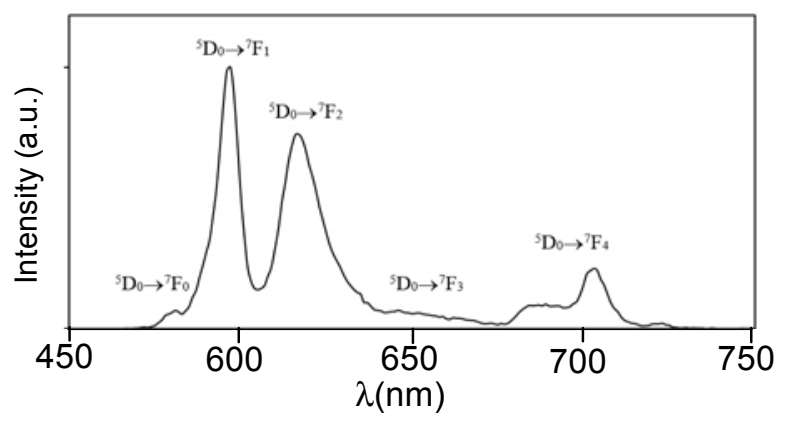

Figure 3. Emission spectra of Eu(III).

\section{SYNTHESIS AND CHARACTERIZATION OF Eu:SrAI ${ }_{2} \mathrm{O}_{4}$}

A new methodology of synthesis derived of the Pechini's method is used to synthesize compositions based on $\mathrm{Eu}$ and $\mathrm{B}$ doped $\mathrm{SrAl}_{2} \mathrm{O}_{4}$. The main characteristics of this method are going to be introduce to the students. Nominal compositions of the samples prepared are summarized in Table 1.

Table 1. Stoichiometry of the samples prepared.

\begin{tabular}{l|c}
\hline \hline Sample & Stoichiometry \\
\hline 1 & $\mathrm{SrAl}_{2} \mathrm{O}_{4}$ \\
\hline 2 & $\mathrm{SrAl}_{1.7} \mathrm{~B}_{0.3} \mathrm{O}_{4}$ \\
\hline 3 & $\mathrm{Sr}_{0.99} \mathrm{Eu}_{0.01} \mathrm{Al}_{1.7} \mathrm{~B}_{0.3} \mathrm{O}_{4}$ \\
\hline \hline
\end{tabular}

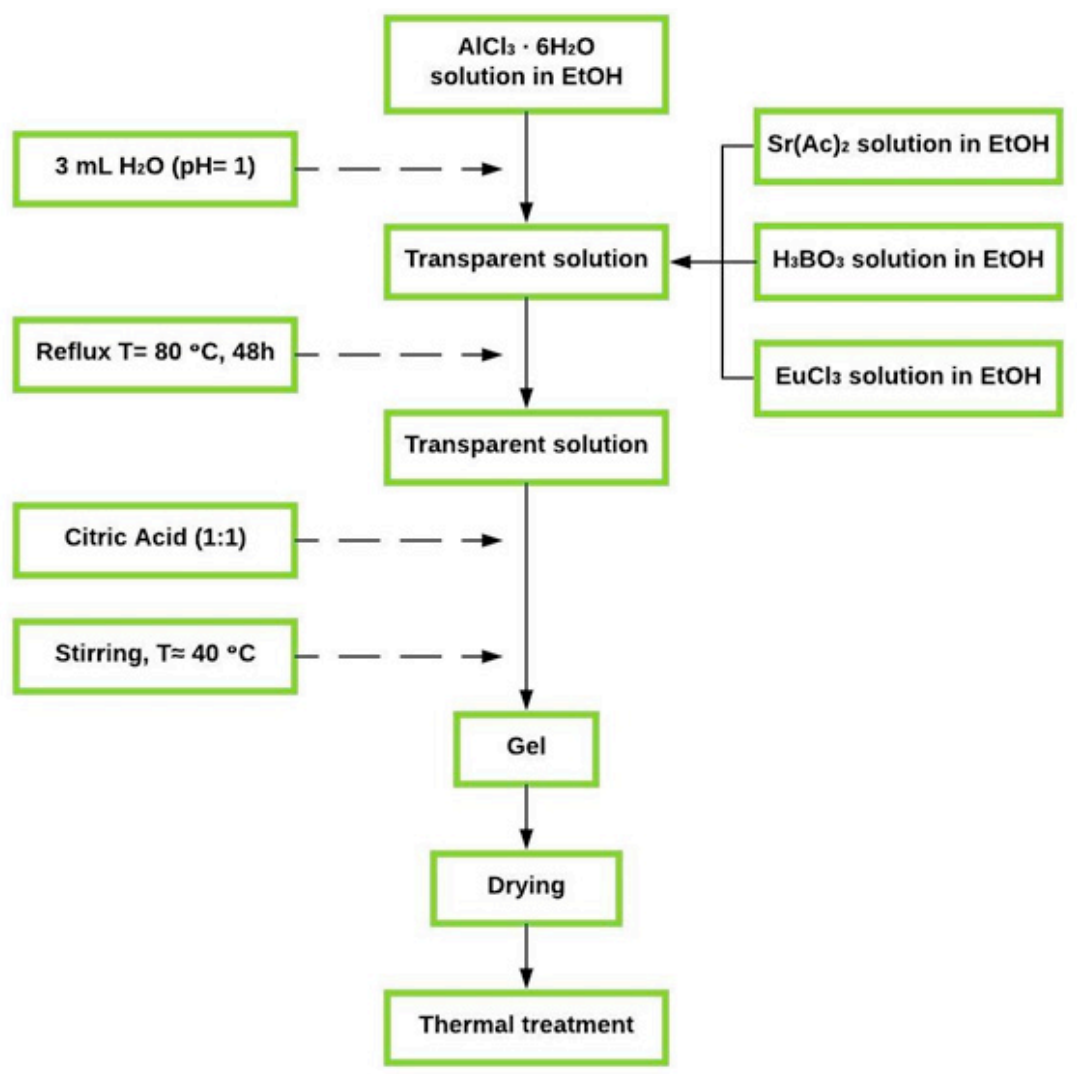

Figure 4. Flow diagram of the experimental procedure. 
Briefly, the quantity of raw materials was calculated for obtaining $6 \mathrm{~g}$ of final product. First, the $\mathrm{AlCl}_{3} \cdot 6 \mathrm{H}_{2} \mathrm{O}(100 \%$, Merck) was dissolved in the minimum quantity of ethanol $(99.8 \%$, Scharlau) $(75$ $\mathrm{mL})$ and $26 \mathrm{~mL}$ of $\mathrm{H}_{2} \mathrm{O}\left(\mathrm{pH}\right.$ 1) was added in order to avoid $\mathrm{Al}\left(\mathrm{CH}_{3} \mathrm{COO}\right)_{3}$ precipitation when the $\mathrm{Sr}\left(\mathrm{CH}_{3} \mathrm{COO}\right)_{2}(100 \%$, Strem Chemicals) solution is added. The $\mathrm{Al}(\mathrm{III})$ solution was stirred to which the ethanolic solutions of $\mathrm{Sr}(\mathrm{II}), \mathrm{H}_{3} \mathrm{BO}_{3}\left(99.8 \%\right.$, Merk) and $\mathrm{EuCl}_{3}(99.9 \%$, Strem) were added. After that, a transparent solution was obtained that was refluxed at $80^{\circ} \mathrm{C}$ for 2 days. Then citric acid in a molar ration 1:1 (citric acid: $\mathrm{M}$ ) is added. The mixture is heated at $40{ }^{\circ} \mathrm{C}$ until a transparent gel is obtained. The resulting gels were then dried and fired in a furnace. A general scheme of the procedure is shown in Fig. 4. Samples were fired in closed crucibles to ensure that organic matter can reduce the $\mathrm{Eu}(\mathrm{III})$ ions to $\mathrm{Eu}(\mathrm{II})$ ions in an electrical furnace at a firing rate of $10^{\circ} \mathrm{C} / \mathrm{min}$ until $1200{ }^{\circ} \mathrm{C}$ and maintained at this temperature for $1 \mathrm{~h}$. At the same time, a sample in an open crucible to avoid any reduction process was prepared for comparison.

\section{RESULTS AND DISCUSSION}

Results obtained by using the techniques mentioned above are explained in this section basing our discussion in a logical PBL.

In order for students to understand the structure of the ceramic material prepared, XRD of the powder obtained by grinding was performed. Fig. 5 shows the diffraction pattern of this ceramic material without and with boron. According to the JCPDS-ICDD patterns, all the main peaks observed were assigned to monoclinic aluminium strontium oxide with a tridymite-like structure (JCPDS-ICDD 74794). The position of the crystallographic planes of this tridymite-like structure are indicated with red lines in Fig. 5 (the main crystallographic planes are also indicated in this figure).
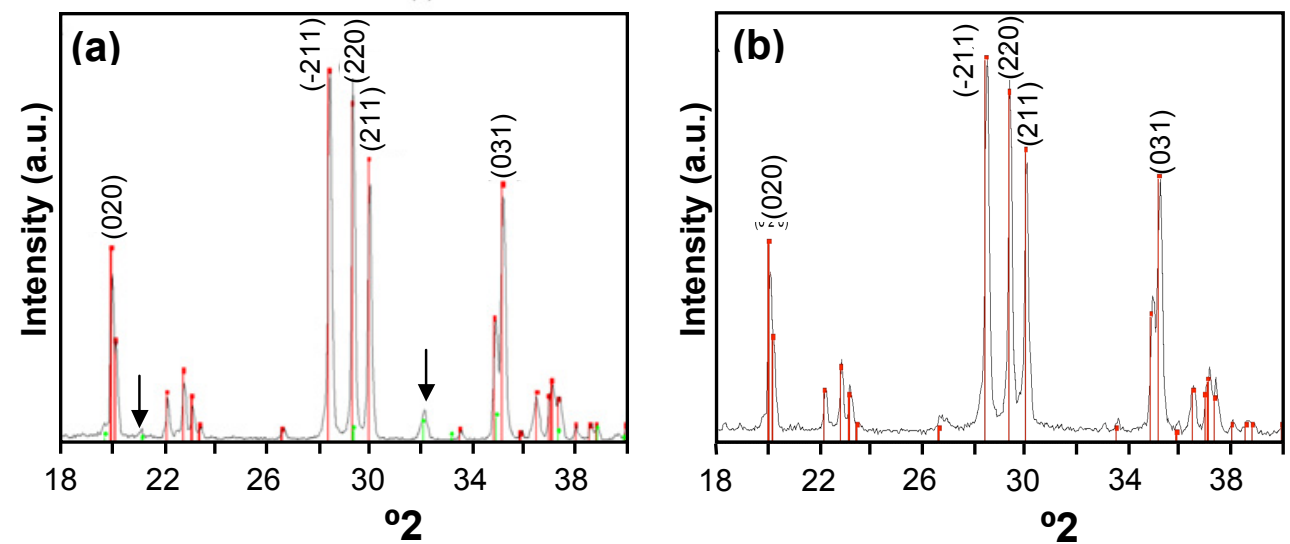

Figure 5. XRD spectra of samples: (a) $\mathrm{SrAl}_{2} \mathrm{O}_{4}$ and (b) $\mathrm{SrAl}_{1.7} \mathrm{~B}_{0.3} \mathrm{O}_{4}$ fired at $1200^{\circ} \mathrm{C} / 1 \mathrm{~h}$.

From XRD results it could also be inferred the addition of $\mathrm{B}_{2} \mathrm{O}_{3}$ is required to obtain the monoclinic $\mathrm{SrAl}_{2} \mathrm{O}_{4}$ polymorph as a single phase at $1200{ }^{\circ} \mathrm{C}$ (Fig. 5a). Secondary phases are observed in this case. The peaks corresponding to this secondary phase are indicated with arrows in Fig. 5a. When boron is added, a single monoclinic phase is obtained at $1200{ }^{\circ} \mathrm{C}$ for both samples, $\operatorname{SrAl}_{1.7} \mathrm{~B}_{0.3} \mathrm{O}_{4}$ stoichiometry (Fig. 5b) and $\mathrm{Sr}_{0.99} \mathrm{Eu}_{0.01} \mathrm{Al}_{1.7} \mathrm{~B}_{0.3} \mathrm{O}_{4}$ (not shown).

At this point, students have analysed the relation between crystallographic planes of the structure and its diffraction pattern.

Then, it's the moment to determine the optical response in order to know if the material prepared have good phosphorescence.

The emission spectra of the sample with europium were registered at two excitation wavelengths: at $340 \mathrm{~nm}\left(\mathrm{Eu}^{2+} 4 \mathrm{f}^{6} 5 \mathrm{~d} \rightarrow 4 \mathrm{f}^{7}\right.$ transition), and $394 \mathrm{~nm}\left(\mathrm{Eu}^{3+5} \mathrm{~L}_{6}\right.$ level) excitation. The resulting emission spectra are depicted in Fig. 6. 

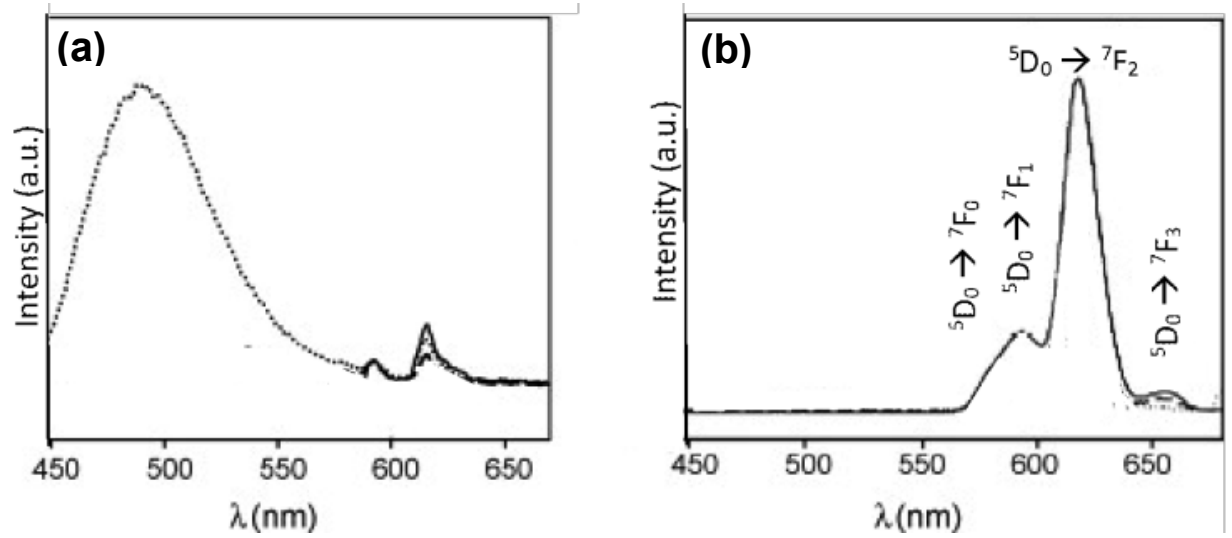

Figure 6. Emission spectra of the $\mathrm{Sr}_{0.99} \mathrm{Eu}_{0.01} \mathrm{Al}_{1.7} \mathrm{~B}_{0.3} \mathrm{O}_{4}$ after annealing at $1200{ }^{\circ} \mathrm{C}$, upon excitation at (left) $340 \mathrm{~nm}$ (a) and $394 \mathrm{~nm}$ (b). They are normalized according to the host independent ${ }^{5}$ $D_{0} \rightarrow{ }^{7} F_{1}$ emission $(590 \mathrm{~nm})$.

All the spectra show the $f-f$ transition bands of $E u(I I I)$, which correspond to the emission from the ${ }^{5} D_{0}$ level to the ground state ${ }^{7} F_{j}(j=0,1,2$ and 3). Upon excitation at $340 \mathrm{~nm}$ wavelength (Fig. 6 , left), the emission spectra show an asymmetrical broad band at $480 \mathrm{~nm}$ originated from $\mathrm{Eu}^{2+}$ interconfigurational $\mathrm{f}-\mathrm{d}$ transitions [11].

Finally, students compared the sample prepared avoiding reduction (open crucible) with that synthesized in reduction atmosphere (close crucible). Results are shown in Fig. 7. The phosphorescent is observed in those samples prepared in reduction atmosphere. Therefore, this effect is produce for the presence of $\mathrm{Eu}(\mathrm{II})$ ion in the host matrix.

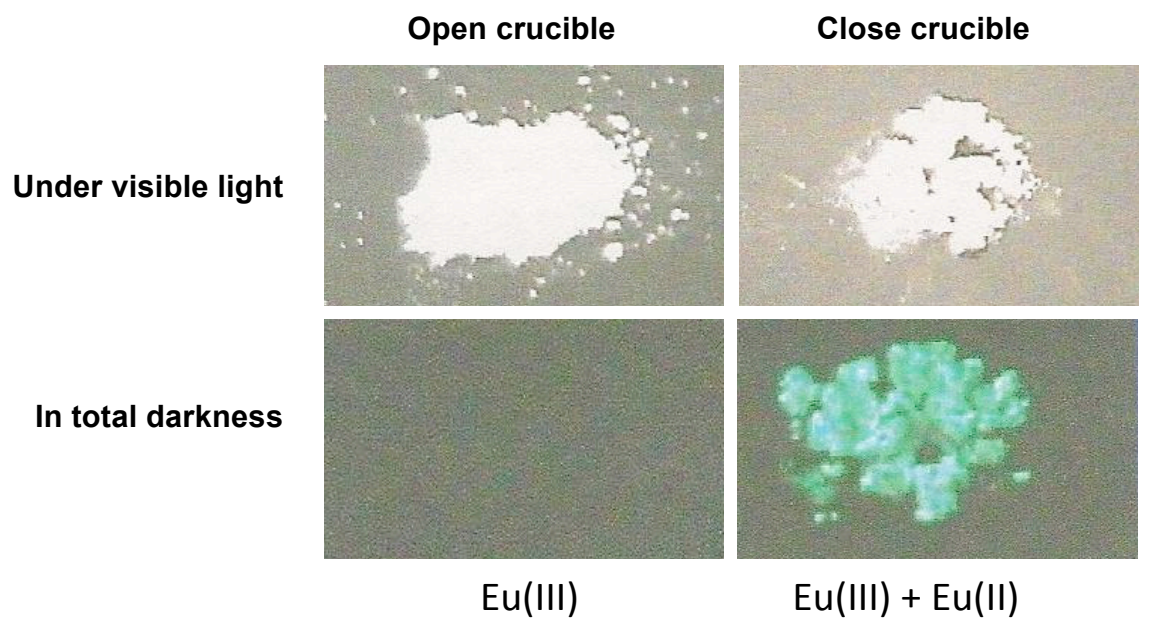

Figure 7. Photographs for comparison between the presence or absence of europium (II) in the composition of the samples.

Using the results obtained so far, students, have checked that the phosphorescence is due to the presence of $\mathrm{Eu}(\mathrm{II})$ and the fluorescence is due to $\mathrm{Eu}(\mathrm{III})$ (the intense band at $620 \mathrm{~nm}$ ).

By following the steps of this work, students are able to understand in detail how a luminescence material works, relating structure, composition and properties of each material.

\section{CONCLUSIONS}

PBL methodology used in this work represents an improvement in the content of the knowledge while simultaneously, it fosters the development of communication, problem-solving and self-directed learning skills. 
X-Ray Diffraction was used in this work to identify the phosphorescent material crystalline phase, while the information of the oxidation state of Eu was studied by emission spectroscopy. XRD analysis showed that phosphorescent material was a single monoclinic phase when boron is present in the structure. Students have discovered that the $\mathrm{Eu}(\mathrm{II})$ is the responsible of the phosphorescence process.

Finally, the discovery of the presence of this type of material in daily life offers a possibility to motivate students to learn these sciences, and allow them to know the importance of the Solid State Chemistry and the Materials Science in our society. Students have achieved a better comprehension about how a glow-in-the-dark stickers, toys or clock dials produce phosphorescence, working together by synthesizing a phosphorescent material, analysing its components, searching information and characterizing the most important part of these compounds.

\section{ACKNOWLEDGEMENTS}

We would like to thank the "Máster en Química Aplicada y Farmacológica" of the Universitat Jaume I, Castellón.

\section{REFERENCES}

[1] D. C. Michael F. Ashby, Hugh Shercliff, Materials: Engineering, Science, Processing and Design. 2009.

[2] X. Ma et al., "Fluorescence Aggregation-Caused Quenching versus Aggregation-Induced Emission: A Visual Teaching Technology for Undergraduate Chemistry Students," J. Chem. Educ., vol. 93, no. 2, pp. 345-350, 2016.

[3] P. B. O'Hara, W. St. Peter, and C. Engelson, "Turning on the Light: Lessons from Luminescence," J. Chem. Educ., vol. 82, no. 1, p. 49, Jan. 2005.

[4] A. L. Jenkins and G. M. Murray, "Enhanced Luminescence of Lanthanides: Determination of Europium by Enhanced Luminescence," J. Chem. Educ., vol. 75, no. 2, p. 227, 1998.

[5] E. Cordoncillo, B. Julian-Lopez, M. Martínez, M. L. Sanjuán, and P. Escribano, "New insights in the structure-luminescence relationship of $\mathrm{Eu}: \mathrm{SrAl}_{2} \mathrm{O}_{4}$, " J. Alloys Compd., vol. 484, no. 1-2, pp. 693-697, 2009.

[6] A. R. Schulze and H. Mueller-Buschbaum, "Compound Formation $\mathrm{MeO}: \mathrm{M}_{2} \mathrm{O}_{3}$. IV. Structure of Monoclinic Strontium Aluminum Oxide $\mathrm{SrAl}_{2} \mathrm{O}_{4}$," Z. Anorg. Allg. Chem., vol. 475, no. 4, pp. 205210, 1981.

[7] M. Marchal et al., "Long-Lasting Phosphorescent Pigments of the Type $\mathrm{SrAl}_{2} \mathrm{O}_{4}: \mathrm{Eu}^{2+}, \mathrm{R}^{3+}(\mathrm{R}=$ Dy, Nd) Synthesized by the Sol-Gel Method," J. Sol-Gel Sci. Technol., vol. 26, no. 1/3, pp. 989992, 2003.

[8] T. Katsumata, K. Sasajima, T. Nabae, S. Komuro, and T. Morikawa, "Characteristics of Strontium Aluminate Crystals Used for Long-Duration Phosphors," J. Am. Ceram. Soc., vol. 81, no. 2, pp. 413-416, 1998.

[9] M. A. Baldo et al., "Highly efficient phosphorescent emission from organic electroluminescent devices," Nature, vol. 395, no. 6698, pp. 151-154, Sep. 1998.

[10] P. Bamfield and M. Hutchings, Chromic Phenomena: Technological Applications of Colour Chemistry. .

[11] J. Sánchez-Benítez, A. De Andrés, M. Marchal, E. Cordoncillo, M. Vallet Regi, and P. Escribano, "Optical study of $\mathrm{SrAl}_{1.7} \mathrm{~B}_{0.3} \mathrm{O}_{4}: \mathrm{Eu}, \mathrm{R}(\mathrm{R}=\mathrm{Nd}$, Dy) pigments with long-lasting phosphorescence for industrial uses," J. Solid State Chem., vol. 171, no. 1-2, pp. 273-277, 2003. 